\title{
Management of Diplopia on Down-Gaze Following Orbital Trauma
}

\author{
J. R. LIPTON, A. B. PAGE, J. P. LEE \\ London
}

\begin{abstract}
Summary
Diplopia in the inferior field due to orbital trauma is a notoriously difficult and disabling problem. Even if a blow-out fracture is repaired by current methods, patients may still have diplopia. There also exists another group in whom no demonstrable radiological fracture can be found, and yet there is a severe down gaze deficit.

The possible mechanisms of this phenomenon are discussed and the results of horizontal muscle transpositon surgery in a series of nine patients is reported.

The authors conclude that this procedure is a valuable method of increasing the useful field of binocular single version in these patients.
\end{abstract}

Much speculation has taken place as to the causes of diplopia in orbital trauma. It is now thought that there are early causes due to soft tissue swelling, oedema, haemorrhage, direct nerve injury, and entrapment of orbital contents in a bony fracture; ${ }^{1}$ late causes are due to fibrosis after pre-existing oedema' and haemorrhage, direct nerve injury, scarring and fixation of previoulsy entrapped tissue. ${ }^{1}$

The generally accepted best management for this type of patient has periodically changed, ${ }^{1,2}$ and at the present time the consensus is that the patient should be watched initially. ${ }^{1,2,3,4}$ In patients who have suffered a blow-out fracture with entrapment of tissue early surgery is usually undertaken where there is diplopia which is not improving after a period of time. ${ }^{2,3,4}$ Various authorities place this at between two and four weeks. Again if there is enophthalmos of $3 \mathrm{~mm}$ or more early surgery should be contemplated. ${ }^{2,3,4}$ Late surgery is performed if an ocular imbalance exists causing diplopia or for a cosmetic problem. , $^{4,6}$ Horizontal rectus muscle surgery for vertical deviations was suggested by Alvaro ${ }^{7}$ in 1950 , but it was Knapp ${ }^{8}$ who described an operation for double elevator underaction, in which the two horizontal rectus muscles could be transposed onto the superior rectus to assist in elevating the globe, which now bears his name. At around the same time horizontal muscle transposition was advocated for double depressor underaction ${ }^{9}$ and inferior rectus muscle paresis. ${ }^{10}$

In our study the patients probably had an injury to either the nerve of the inferior rectus or the inferior rectus muscle itself causing a persistent limited depressor paresis. We felt that by transposing the horizontal recti onto the inferior rectus, this would improve the depressor action of the globe and increases the field of binocular single vision. For the purpose of this paper, we have termed this the inverse Knapp procedure (Fig. 1).

\section{Patients and methods}

Nine patients were recruited, five male, four

From: Moorfields Eye Hospital, London.

Correspondence to: J. P. Lee, FRCS, FCOphth, Moorfields Eye Hospital, City Road, London EC1V 2PD. 


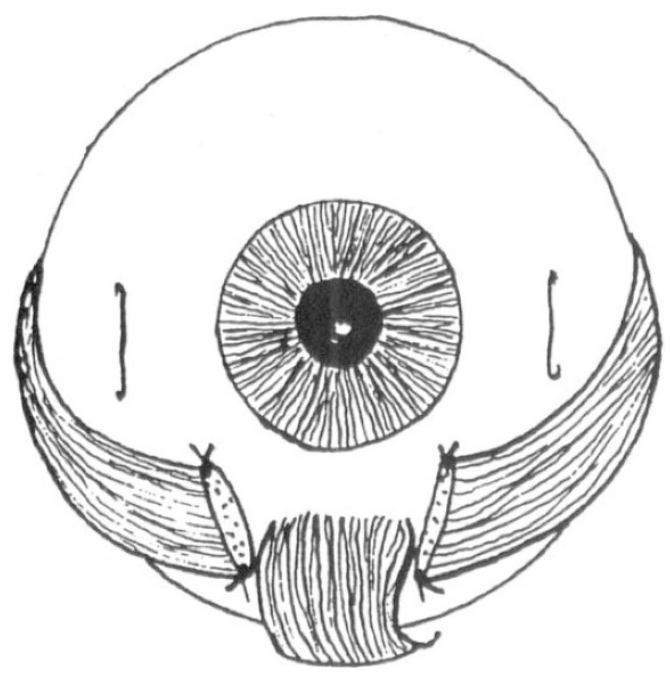

Fig. 1. Muscle placement for an inverse Knapp procedure.

female, average age 27 years 8 months (range 7-61 years). Six patients, three male and three female, had had orbital floor explorations with release of entrapped tissue following blow-out fractures and after this procedure they still had been left with a significant depressor deficit even allowing an average of nine months (range 8-11) between operations. Of the remaining three patients, two male and one female, an average of two years (range 8-48 months) elapsed between the original insult and the inverse Knapp procedure. At the time of surgery a forced duction test in all cases appeared normal.

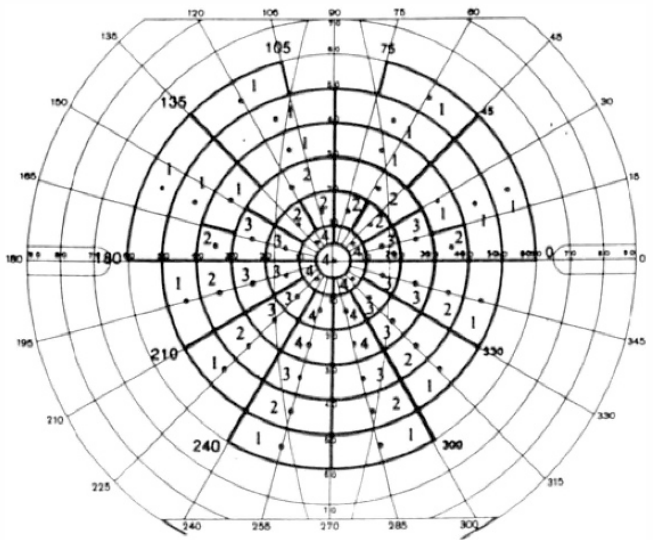

Fig. 2. The scoring template overlaid on a chart for recording binocular single vision.
Several methods are available, all up to recently graphical, to record the binocular single vision. In 1987 Woodruff et al put forward a scoring template, ${ }^{11}$ which gave a numerical value to a binocular single vision field (Fig. 2). This template gives a higher value to the central field as opposed to a lower value for the more peripheral field. We scored, using Woodruff's template, the field of binocular single vision for the complete, inferior half, and superior half fields. The results are converted into a percentage score and are given in Table I.

One patient had no binocular single vision demonstrable at all, though he obtained a very satisfactory cosmetic result. The patient is not included in the results.

\section{Results}

The results in Table I show that the field of binocular single vision increases from an average of $31 \%$ (4-68\%) pre surgery to $52 \%$ (16$84 \%$ ) one week post surgery for the complete field. Further improvement is found to take place and at a minimum of six months post surgery the average has risen to $64 \%$ (16-92\%).

Similarly for the superior and inferior half fields the pre surgical average is $44 \%(6-96 \%)$ and $21 \%(0-52 \%)$ respectively. One week post surgery the averages had improved to $51 \%(18-80 \%)$ and $48 \%(13-85 \%)$. Further improvement again is seen long term, the values being $67 \%(20-96 \%)$ and $59 \%$ (16$91 \%$ ) respectively.

The patients were followed up for an average of 14.9 months (6-36 months) and it is interesting to note that three patients did not show any improvement beyond the first postoperative week, while one still continues to

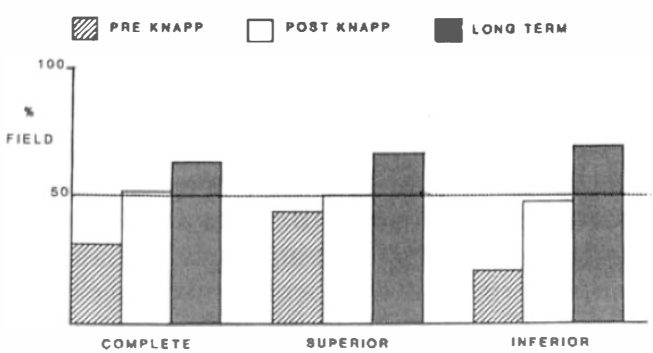

Fig. 3. Surgical outcome for the complete, superior and inferior fields as a percentage represented as a bar graph. 
Table I Surgical outcome

\begin{tabular}{lccc}
\hline$\%$ Field & Pre Knapp & Post Knapp & Long Term \\
\hline Complete & $31(4-68)$ & $52(16-84)$ & $64(16-92)$ \\
Superior & $44(6-96)$ & $51(18-80)$ & $67(20-96)$ \\
Inferior & $21(0-52)$ & $48(13-85)$ & $59(16-91)$ \\
\hline
\end{tabular}

show improvement 20 months after the inverse Knapp procedure. It should also be noted that there were no induced horizontal deviations or significant side effects.

\section{Discussion}

Some patients develop a depressor deficit without radiological evidence for a fracture and it does not improve with time. This is evidence that the inferior rectus muscle is not working properly. We have already mentioned that there may be soft tissue swelling and disruption to the nerve directly due to ocular trauma, but it has also been found that a haematoma can arise in the muscle itself, ${ }^{12}$ causing fibrosis and subsequent loss of function. This probably explains why the five patients who had previous orbital floor surgery did not show any improvement.

If vertical muscle surgery is performed on the affected globe, that is a superior rectus recession and inferior rectus resection, the primary position of the eye is improved, however the depressor defect still exists as nothing has been done for the dynamic range of the eye in the vertical plane.

In performing an inverse Knapp procedure, it is reasonable to assume that the complete and inferior fields should improve, however, why should an improvement in the superior field take place? The possible explanations for this phenomenon must include the following: (1) The scoring template is centrally weighted so a superior field of binocular single vision when drawn down to the primary position will score more highly.

(2) The superior rectus now has an antagonist and thus allows it a better mechanical action, so increasing the field and score.

(3) Contracture of the superior rectus has probably taken place, and that this is now From: Moorfields Eye Hospital, London. reversed, so increasing the binocular single vision field and score.

Furthermore an improvement which continues long after the original surgery is unusual. It might be argued that the inferior rectus is recovering, but why should this happen after such a long period of time from the original insult. Far more likely is that contracture of the superior rectus due to its unopposed action has taken place and is now gradually being reversed. This may explain why some patients continue to show improvement long after the original surgery.

In conclusion, this procedure is a valuable method of increasing the useful field of binocular single vision in patients with blow-out fractures and diplopia in the inferior field.

\section{Réferences}

${ }^{1}$ Koornneef L: Current concepts on the management of orbital blow-out fractures. Ann Plast Surg 1982, 9: 185-200.

${ }^{2}$ Wilkins RB and Havins WE: Current treatment of blow-out fractures. Ophthalmology 1982, 89: 464-6.

${ }^{3}$ Dulley B and Fells P: Long-term follow-up of orbital floor blow-out fractures with and without surgery. Mod Probl Ophthalmol 1975, 14: 467-70.

${ }^{4}$ Putterman AM, Stevens T, Urist MJ: Nonsurgical management of blow-out fractures of the orbital floor. Am J Ophthalmol 1974, 77: 232-9.

${ }^{5}$ Emery J, Noorden GK von, Schlernitzauer DA: Orbital floor fractures: Long-term follow-up of cases with and without surgical repair. $\operatorname{Tr} \mathrm{Am}$ Acad Ophthalmol Otolanyngol 1971, 75: 802-11.

${ }^{6}$ Gilbard SM, Mafee MF, Lagouros PA, Langer BG: Orbital blow-out fractures: The prognostic significance of computer tomography. Ophthalmology 1985, 92: 1523-8.

${ }^{7}$ Alvaro M: Simultaneous surgical correction of vertical and horizontal deviations. Ophthalmolog. ica1950, 120: 191-7.

${ }^{8}$ Knapp P: The surgical treatment of double-elevator paralysis. Tr Am Ophthalmol Soc 1969, 67: 304-23.

${ }^{9}$ Dunlap EA: Vertical displacement of horizontal rectus. Symposium on Strabismus. St Louis, CV Mosby Co 1971, 307-29.

${ }^{10}$ Metz HS: Saccades with limited downward gaze. Arch Ophthalmol 1980, 98: 2204-5.

${ }^{11}$ Woodruff G, O'Reilly C, Kraft SP: Functional scoring of the field of binocular single vision in patients with diplopia. Ophthalmology 1987, 94: 1554-61.

${ }^{12}$ Heinze J: Cranial nerve avulsion and other neural injuries in road accidents. Med J Austral 1969, 2: 1246-9.

Correspondence to: J. P. Lee, FRCS, FCOphth, Moorfields Eye Hospital, City Road, London EC1V 2PD. 